\title{
HISTÓRIA DE USUCAPIÃO EM TERRAS DEVOLUTAS: PERCEPÇÕES OFERECIDAS POR UMA OBRA JURÍDICA DE 1943
}

\section{HISTORY OF USUCAPION IN UNTITLED PUBLIC LANDS: PERCEPTIONS OFFERED BY A 1943 WORK}

\author{
Cláudio Grande Júnior \\ Procuradoria-Geral do Estado de Goiás (PGE-GO) - (Goiânia, GO, Brasil)
}

Recebimento: 21 fev. 2017

Aceitação: 29 abr. 2017

\begin{abstract}
Como citar esta resenha / How to cite this review (informe a data atual de acesso / inform the current date of access):

GRANDE JÚNIOR, Cláudio. História de usucapião em terras devolutas: percepções oferecidas por uma obra jurídica de 1943. Revista da Faculdade de Direito UFPR, Curitiba, PR, Brasil, v. 62, n. 2, p. 285 - 294, maio/ago. 2017. ISSN 2236-7284. Disponível em: <http://revistas.ufpr.br/direito/article/view/50820>. Acesso em: 28 ago. 2017. DOI: http://dx.doi.org/10.5380/rfdufpr.v62i2.50820.
\end{abstract}

\section{PALAVRAS-CHAVE}

Usucapião. Terras devolutas. Propriedade territorial privada. Código Civil de 1916. História do direito.

\section{KEYWORDS}

Usucapion. Untitled public lands. Private territorial property. Brazilian Civil Code of 1916. History of law.

O livro Terras devolutas e prescrição é, antes de tudo, uma apaixonada defesa da usucapião sobre terras devolutas, visando a proporcionar, nos anos 1940, uma solução jurídica para a regular constituição da propriedade privada sobre as terras devolutas apossadas por particulares, principalmente no interior do estado de São Paulo, décadas antes, durante o boom da cafeicultura.

Verbete biográfico do Centro de Pesquisa e Documentação de História Contemporânea do Brasil (CPDOC) da Fundação Getulio Vargas (FGV) informa que o autor, Carlos Castilho Cabral, era paulista, graduou-se pela Faculdade de Direito de São Paulo, em 1929, e começou suas atividades advocatícias no oeste daquela unidade federativa. Logo em seguida, sobrevindo a Revolução de 1930, ingressou na política. Mas, com a implantação da ditadura do Estado Novo, em 1937, voltou a se dedicar à advocacia, desenvolvendo paralelamente atividades agrárias. Em 1940, tornou-se membro do conselho superior do Instituto dos Advogados Brasileiros (IAB), representando a advocacia brasileira até em eventos no exterior. 
Em 1943, realizou-se, no Rio de Janeiro, o Congresso Jurídico Nacional, em comemoração ao centenário do IAB. O evento é historicamente conhecido pela desavença com a ditadura de Vargas, envolvendo inclusive Castilho Cabral. Todavia, o que mais nos interessa é o fato de, nesse congresso, Castilho Cabral ter apresentado sua tese Terras devolutas e prescrição, criticando as tentativas dos governos de Vargas de impedir a usucapião sobre terras devolutas e públicas. O texto foi publicado como o livro, ora resenhado.

No currículo constante da obra, o autor se apresentou como do conselho superior e da comissão permanente de problemas de após-Guerra do IAB; da American Society of International Law; e da Federação Interamericana de Advogados, comissão permanente de Direito Administrativo.

Posteriormente, Castilho Cabral colaborou para a fundação da União Democrática Nacional (UDN), em 1945. Foi deputado federal por São Paulo, de 1951 a 1954, pelo Partido Social Progressista (PSP). Reelegeu-se, em 1954, pelo Partido Trabalhista Nacional (PTN). Logo se licenciou, por alguns meses, para ser secretário de trabalho, indústria e comércio do estado de São Paulo, nomeado pelo governador Jânio Quadros. Retornou à Câmara dos Deputados Federais, cumprindo mandato até janeiro de 1959, quando sua legislatura findou. Paralelamente, foi eleito para a diretoria da Federação das Associações Rurais do Estado de São Paulo, permanecendo até 1961. Integrou o governo do presidente Jânio Quadros. Porém, com a renúncia deste, encerrou a carreira política, voltando-se às atividades agrárias às margens do rio Paraná. Prosseguiu participando de eventos da Ordem dos Advogados do Brasil (OAB) e missões comerciais no exterior. Além da obra aqui resenhada, publicou Batalhões patrióticos na Revolução de 1924 (1927) e Tempos de Jânio e outros tempos (1962). Faleceu em 1971.

Terras devolutas e prescrição é um livro com 120 páginas, dividido em 29 breves capítulos, antecedidos por uma introdução. Os títulos dos capítulos constam apenas no sumário, mas não nos textos dos próprios, que foram apenas numerados. Por sua vez, o sumário traz somente os títulos dos capítulos, porém sem numeração, o que retarda a compreensão da obra e dificulta a realização de consultas a trechos específicos.

A expressão “prescrição”, constante no título do livro, tem o significado de "prescrição aquisitiva”. Atualmente, quem for escrever sobre o assunto provavelmente preferirá utilizar a palavra “usucapião”. Esta, contudo, só fora introduzida na legislação brasileira pelo Código Civil de 1916, que contava com apenas 26 anos de vigência quando Castilho Cabral elaborou a tese, ao passo que a expressão “prescrição aquisitiva” era utilizada há séculos pelos operadores do direito luso-brasileiro. A diferença não é meramente formal de nomenclatura, mas também substancial, porque a usucapião, disciplinada de 1916 em diante pelo Código Civil, pode ser invocada tanto como meio defensivo 
como ofensivo, sendo hoje normalmente mais utilizada na segunda vertente, por iniciativa do possuidor, interessado em constituir a propriedade na forma de um título, a ser registrado no cartório imobiliário competente e oponível indistintamente contra todos. Já a prescrição aquisitiva, no direito brasileiro de até 1916, era fundamentalmente um meio de defesa, porque se admitia a demonstração e comprovação da propriedade por outras formas que não necessariamente o registro imobiliário erga omnes de um título de domínio dotado de exatidão. Por isso se encontra tanto, na historiografia, a informação de que a Lei de Terras de 1850 não surtiu os efeitos esperados, pois a maioria dos fazendeiros simplesmente não tinha interesse prático na obtenção de um título preciso e inequívoco de domínio. A propriedade sobre a terra era reflexo concreto do uso da força exercido contra indígenas, escravos, agregados e outras gentes do campo, bem como, simultaneamente, da obtenção de algum consenso com os fazendeiros vizinhos. Nessa linha, Castilho Cabral defende "os que entram pelo sertão, munidos de um título, cuja melhor defesa está na efetiva ocupação” (p. 96), e afirma que “a ‘ocupação primária’ é assim, a origem de quasi toda a propriedade fundiária, a propriedade territorial no Brasil: a prescrição ou usucapião, a sua consolidação e garantia” (p. 39). Tratando especificamente sobre o caso do estado de São Paulo, destaca (p. 95):

Até 1931, o Estado de S. Paulo se conformou com a prescritibilidade das terras devolutas, não tomando qualquer atitude eficiente contra os particulares desbravadores, (antes, os incentivava) conservando-se fiel à orientação dos que viam na iniciativa particular, em matéria de desbravamento e colonização, a melhor política territorial, de acordo com o "sentido" tradicional do direito de propriedade em nosso país, sempre garantido e consolidado pela prescrição ou usucapião.

A introdução chama a atenção para a atualidade, àquele tempo, do problema da prescritibilidade dos bens públicos dominicais e, especialmente, das terras devolutas, devido "à radical mudança de atitude governamental, em relação ao desbravamento dos sertões”, a partir da Revolução de 1930. Cita a excessiva benevolência da Lei Paulista n 1.844, de 1921, “jubileu do grileiro”, e o extremado rigor do Decreto n 5.133, de 1931, “pelourinho do desbravador”. No plano nacional, menciona os intensos debates provocados pelo anteprojeto federal de uma "lei de terras", pelo qual se regulamentaria também a “ação discriminatória” como uma “ação especial”.

Realmente, o autor escreveu no que parece ter sido o auge da discussão sobre a possibilidade de usucapião de terras devolutas e de bens públicos dominicais em geral. Para entendê-la, são necessárias explicações preliminares.

Abatido o regime sesmarial, a típica propriedade privada territorial brasileira do século XIX resultava da ocupação, do uso da força sobre habitantes do campo e de certo consenso com os vizinhos igualmente poderosos da localidade. Contudo, desamparada de título preciso formalmente 
reconhecido pelo Estado, apresentava o problema de ser uma mercadoria de difícil circulação, porque não dispunha da segurança jurídica mínima necessária para servir de garantia ao crédito, no contexto de uma proposta política de financiamento agrário que os sucessivos governos sentiam, cada vez mais, a necessidade de desenvolver em nosso País.

Por esse e outros motivos, a Lei de Terras do Império (Lei $n^{\circ}$ 601, de 1850) proibiu novos apossamentos de terras devolutas, estabelecendo a necessidade da expressa aquiescência do Estado, em regra mediante compra e venda, excepcionalmente por meio de doação (arts. $1^{\circ}$ e $2^{\circ}$ ). Ao mesmo tempo, essa lei previu o instituto jurídico da legitimação de posse, para a definitiva transferência ao domínio privado das terras então apenas possuídas por particulares. Todavia, o Regulamento de 1854 (Decreto $n^{0} 1.318$ ) restringiu bastante o alcance prático da legitimação de posse, porque reconheceu a plena propriedade privada da terra à boa parte dos possuidores àquela época (arts. 22 a 27), sem necessidade “de legitimação, nem de novos titulos para poderem gozar, hypothecar, ou alienar os terrenos, que se achão no seu dominio” (art. 23). Cabia ao Poder Público localizar, identificar e demarcar suas terras devolutas, para lhes conferir algum uso público ou destiná-las à alienação. Mas não foi o que, de ordinário, aconteceu no decorrer do Império. Assim, os proprietários de terras continuaram expandindo suas posses sobre as áreas devolutas limítrofes e muitos outros indivíduos deram início a novos apossamentos de terras devolutas.

A partir de 1894, no alvorecer da República, as posses contrárias à legislação imperial de terras começavam a completar quarenta anos, prazo na época aceito, pela comunidade jurídica nacional, para a objeção da prescrição aquisitiva em desfavor do Poder Público. A maioria das terras devolutas fora transferida aos Estados-membros, que, em regra, não se esforçaram em identificá-las e regularizar os respectivos posseiros. Prevaleceu, igualmente, a inércia da União quanto à apuração e administração das terras devolutas que permaneceram sob seu domínio.

O Rio Grande Sul costuma ser apontado como uma exceção - estado no qual foi executada uma política mais séria de terras, com a discriminação, demarcação, cadastro e registro de terras devolutas, para a subsequente alienação aos particulares, evitando-se as ocupações ilegais e grilagens de terras, que ocorriam em número muito maior nas outras unidades federativas.

No decorrer da República Velha, o estado de São Paulo simplesmente assistiu ao apossamento não autorizado de boa parte de suas terras devolutas, o que fez com a clara intenção de não prejudicar a veloz expansão cafeeira em curso, acompanhada da fundação de dezenas de novas cidades no interior paulista. A Lei Paulista ${ }^{\circ}$ 323, de 1895, não se afastava da legislação imperial, considerando particulares apenas as terras dotadas de título legítimo de domínio admitido pelo Regulamento de 1854 da Lei de Terras do Império e as, depois disso, validamente destacadas do 
patrimônio público. Todas as outras posses precisavam ser legitimadas, o que incluía a enormidade de terras apossadas por particulares no interior paulista, de 1854 em diante. A comoção causada logo levou à promulgação da Lei Estadual $\mathrm{n}^{0}$ 545, de 1898, automaticamente legitimando, “independentemente de processo" (art. $2^{\circ}$ ), as posses que, na data de publicação desse diploma legal, contavam com 20 ou 30 anos, conforme as hipóteses previstas. Castilho Cabral elogia a norma, por entender que resgatou o consagrado “'sentido’ tradicional da propriedade no Brasil!” (p. 77-79), que independia de um título ou papel concedido pelo Estado (p. 118).

Como se sabe, os apossamentos continuaram freneticamente, depois disso. Claramente visando a regularizá-los, foi promulgada a Lei Paulista $\mathrm{n}^{0}$ 1.844, de 1921, alcunhada de "jubileu do grileiro”, segundo Castilho Cabral, porque autorizava o governo a conceder título de domínio a praticamente qualquer pessoa que tivesse começado sua posse um ano antes da publicação desse diploma legal. A Revolução de 1930 encerrou a festa, revogando a lei por meio do Decreto Estadual $n^{0}$ 5.133, de 1931, amparado no revolucionário Decreto Federal $n^{0}$ 19.398, de 1930. Editado com força de lei, considerava terras devolutas as que não haviam sido legitimadas ou revalidadas, nos termos das leis anteriores, e as que não "estavam na posse ou sob o domino particular por qualquer titulo legitimo anterior a $1 .^{\circ}$ de Janeiro de $1877^{\prime \prime}$ (art. $1^{\circ}$ ). Mais do que isso, estabelecia serem nulas “as posses feitas em terras devolutas posteriormente a $1 .^{\circ}$ de janeiro de 1877” (art. 30) e determinava que todas as posses anteriores, com ou sem título, deveriam "ser justificadas de acordo com o disposto” no decreto (art. 31). Daí concordou Castilho Cabral com o apelido, dado ao decreto, de “pelourinho do desbravador”. De fato, o ato normativo vai ainda mais longe, excluindo expressamente, em seu art. 49, a hipótese de aquisição de terras devolutas por usucapião, o que é alvo de censura pelo autor, pois os Estados-membros não tinham competência para legislar sobre direito civil. A crítica procede apenas em parte, porque o mencionado dispositivo faz remissão à legislação federal, mais exatamente ao art. 67 do Código Civil de 1916 e ao Decreto n ${ }^{0} 19.924$, de 1931. A leitura atual mais óbvia desse quadro normativo é a de que simplesmente proibia a usucapião sobre bens públicos, inclusive terras devolutas. Entretanto, Castilho Cabral faz uma leitura completamente diferente e, por mais incrível que pareça hoje, perfeitamente condizente com grande parcela da doutrina jurídica e jurisprudência da época, como se demonstra a seguir.

O pensamento jurídico nacional se desenvolveu, no século XIX, no sentido de se admitir a prescritibilidade de certas “cousas” do Estado que, atualmente, corresponderiam aos bens públicos dominicais. A Consolidação Teixeira de Freitas se encontrava bem organizada nesse sentido. Todavia, a falta de clareza do Código Civil de 1916, nesse ponto, abriu margem a uma enorme polêmica, que se estendeu até 1963, quando finalmente o Supremo Tribunal Federal firmou posição 
no sentido da imprescritibilidade de todas as categorias de bens públicos, editando a Súmula $n^{\circ} 340$ (“Desde a vigência do Código Civil, os bens dominicais, como os demais bens públicos, não podem ser adquiridos por usucapião.”), que influenciou decisivamente o pensamento jurídico nacional a partir de então. Todavia, Castilho Cabral escreveu seu livro 20 anos antes, quando a disputa ainda pendia para a tese contrária, fato pouco conhecido dos juristas da atualidade.

O art. 65 do Código de 1916 definia bens públicos, o art. 66 os classificava e o dispositivo seguinte dispunha: “Art. 67. Os bens de que trata o artigo antecedente só perderão a inalienabilidade, que lhes é peculiar, nos casos e forma que a lei prescrever.” Não há dispositivo tratando direta e inequivocamente a imprescritibilidade dos bens públicos. Alguns juristas e operadores do direito é que interpretaram a imprescritibilidade como decorrência lógica da inalienabilidade do art. 67 do CC/1916, iniciando o embate ao discurso jurídico até então dominante.

Portanto, tem razão Castilho Cabral ao escrever que “os bens públicos patrimoniais eram, no regime anterior ao Código Civil, prescritíveis” e que a controvérsia surgiu da redação defeituosa dos arts. 66 e 67 do CC/1916 (p. 80). Contudo, exagera ao afirmar (p. 81) que “a corrente da maioria esmagadora dos nossos juristas [...] sustenta, com inteiro apoio da melhor hermenêutica, a prescritibilidade dos bens patrimoniais do Estado, mesmo depois da entrada em vigor do Código Civil”, e que “a jurisprudência continuou, sem discrepância de vulto, a admitir a prescrição das terras devolutas depois do Código Civil”. São válidas as listas, apresentadas, de juristas e de julgados favoráveis à prescritibilidade das terras devolutas após 1916 (p. 92-94). Mas, na verdade, nos primeiros anos de vigência da codificação, foram travadas intensas batalhas doutrinárias sobre a prescritibilidade dos bens dominicais, envolvendo principalmente Clóvis Beviláqua, Reynaldo Porchat, J. M. Azevedo Marques, Spencer Vampré e Daniel Serapião de Carvalho. Os debates se estenderam aos tribunais, podendo ser encontrados alguns julgados pela imprescritibilidade de todos os bens públicos, como uma decisão de 1924, de Minas Gerais (RF 46/33), e decisões de 1925, de São Paulo (RT 57/161) e Santa Catarina (RF 46/270). Mas, depois, pelo menos no Tribunal de Justiça de São Paulo (TJSP), há um número maior de decisões pela prescritibilidade dos bens públicos dominicais, como as apontadas nas RT 71/110, 73/338, 77/157, 74/356, 78/110 e 331, 78/109, 79/354 e 82/371, proferidas entre 1929 e 1932.

Nosso sistema jurídico tendia para a prescritibilidade dos bens dominicais, quando sobreveio a Revolução de 1930. Entretanto, não interessava ao novo governo a usucapibilidade de certos bens públicos, especialmente as terras devolutas. Logo, foi baixado, com força de lei, o Decreto $\mathrm{n}^{\circ} 19.924$, de 1931, estabelecendo sobre terras devolutas: 
Art. $1^{\circ}$ Compete aos Estados regular a administração, concessão, exploração, uso e transmissão das terras devolutas, que lhes pertencem, excluída sempre (Cód. Civil, arts. 66 e 67) a aquisição por usucapião, e na conformidade do presente decreto e leis federais aplicáveis.

A interpretação mais natural do dispositivo é a de que ele reiterava a competência dos Estados-membros para legislar sobre suas terras devolutas, porém vedando a possibilidade de particulares adquirirem terras devolutas por usucapião, afirmando que isso constava, inclusive, dos arts. 66 e 67 do CC/1916. No entanto, várias outras interpretações ganharam repercussão, sendo uma delas a constante da obra aqui resenhada (p. 97-99). Ela retrata que o decreto distinguiu duas circunstâncias nas quais ocorreria a disposição de terras devolutas: (i) transmissão ou alienação voluntária; e (ii) aquisição unilateral ou usucapião. Defende que teria sido delegado aos Estados a faculdade de legislar apenas sobre a primeira dessas circunstâncias, reservando-se a segunda à União, “o que vem comprovar o acerto daqueles que negaram aos Estados a competência para legislar sobre a matéria de direito substantivo”, no caso, direito civil, mais exatamente usucapião. "E mais, ainda, com a referência aos artigos 66 e 67 do Código Civil, o dec. 19.924 demonstra que a matéria continua sujeita às normas do direito comum, do direito civil.”. Conclui, assim, que, com o decreto, ter-se-ia tentado impedir os estados de legislar sobre direito substantivo, mais especificamente usucapião, deslize, aliás, frequente ao longo da República Velha e muito criticado pelo autor. "A referência ao usucapião, portanto, aí está no dec. 19.924, apenas para subtraí-lo da legislação estadual; não para destruir o instituto.”

Dada a resistência da comunidade jurídica, cujo um dos baluartes foi a interpretação acima, sobreveio outro decreto com força de lei, o $\mathrm{n}^{\circ}$ 22.785, de 1933, desta vez enunciando a imprescritibilidade de todos os bens públicos de forma bem clara: “Art. $2^{\circ}$ Os bens públicos, seja qual fôr a sua natureza, não são sujeitos a usocapião.” Na exposição de motivos é afirmado:

Considerando ainda que, embora no direito patrio os bens públicos, mesmo dominicais, já sejam insuscetiveis de usocapião, a circuntancias de se terem manifestado em contrário, algumas opiniões torna conveniente que o legislador volte a reafirmar esse: princípio que é de ordem pública;

Desde então, não havia mais dúvidas de que a imprescritibilidade constava no ordenamento jurídico. Vários defensores da prescritibilidade de certos bens públicos reconheceram-se derrotados, mas excepcionando que a proibição só valeria daquele momento em diante. Em outras palavras, aceitaram a imprescritibilidade de todos os bens públicos somente do início da vigência, em diante, do Decreto $\mathrm{n}^{0}$ 22.785, de 1933, jamais de forma retroativa. O autor da obra aqui resenhada foi um deles (p. 103): 
Criando realmente direito novo, surgiu posteriormente, em 31 de maio de 1933, o decreto federal n. 22.785 em que, pela primeira vez, expressamente, se proibiu o usocapião sobre os bens públicos

[...]

Este decreto é a primeira lei federal, substantiva, promulgada por Poder competente de acordo com a nossa organização constitucional, a estabelecer a imprescritibilidade das terras devolutas, envolvidas na expressão geral da lei.

Essa é a questão central do livro, que foi redigido exatamente para defender o ponto de vista acima transcrito. Toda a extensa regressão histórica que o autor faz é empenhada em tentar demonstrar a inexistência anterior de norma, no direito brasileiro, proibindo a prescrição aquisitiva sobre bens públicos não afetados a um uso público, principalmente terras devolutas. Com igual propósito é que são tratadas todas as demais questões jurídicas secundárias levantadas ao longo da obra, para se opor aos partidários da imprescritibilidade retroativa, com o objetivo prático de garantir a propriedade em favor dos particulares que se apossaram de terras devolutas décadas antes, principalmente no interior de São Paulo, quando da expansão acelerada da cafeicultura (p. 103-104):

E, no entanto, sem embargos de evidente contradição doutrinária, é sobre esse decreto federal que nossos opositores assentam, com ares de triunfo, a sua tese de imprescritibilidade retroativa, pretendendo entendê-lo simples lei interpretativa do Código Civil cujas normas sempre procuraram afastar do campo das terras devolutas $[\ldots]$

Evidente, no entanto, é que esse decreto federal, de acordo com a sistemática do nosso direito e da boa hermenêutica, só atinge as prescrições não consumadas, as prescrições em curso, e não aquelas que, antes da publicação, tinham já reunido todos os requisitos da aquisição do domínio pela usucapião.

Contra a tese da retroatividade da lei interpretativa, após citar vários juristas, busca guarida nas lições do conceituado Carlos Maximiliano, constantes do célebre livro Hermenêutica e Aplicação do Direito, de 1925, segundo as quais inexiste propriamente interpretação autêntica, porque o ato legislativo subsequente, na verdade, traria sempre uma nova norma, ainda que a pretexto de interpretar a anterior (p. 107-108).

Hoje, uma leitura anacrônica, a partir exclusivamente da Súmula nº 340, pode levar à falsa conclusão de que Castilho Cabral e os demais partidários da irretroatividade do decreto de 1933 não lograram êxito. É uma visão equivocada. Na verdade, eles alcançaram sucesso imediato e seguiram vencendo jurisprudencialmente até os anos de 1960, sofrendo surpreendente revés somente com a publicação da Súmula, em 1963. Ao tempo da obra resenhada já havia julgados importantes no sentido da irretroatividade e alguns foram citados na obra. Cumpre advertir apenas que muitas decisões consideram o anterior Decreto $n^{\circ}$ 19.924, de 1931, como marco inicial da imprescritibilidade das terras devolutas, mas de forma igualmente irretroativa. 
Retornando ao livro, este começa com um extenso histórico, pregado com o objetivo de afastar todo e qualquer pressuposto que pudesse ser invocado em defesa da imprescritibilidade dos bens públicos dominicais antes dos decretos de 1931 e 1933 e, até mesmo, do Código de 1916. Assim, ataca a ideia de “domínio eminente” do Estado, utilizada por alguns juristas da época para justificar a dominialidade pública das terras devolutas (cap. 1 a 7). Contra o "fantasma aterrador do domínio eminente” e apontando o fracasso do sistema sesmarial, sustenta que a “ocupação primária” é a origem de quase toda propriedade fundiária no Brasil e “a prescrição ou usucapião, a sua consolidação e garantia” (cap. 8).

Prossegue narrando sobre a ocupação dos sertões pelos bandeirantes e a aplicação do princípio do uti possidetis, tanto no plano internacional como "nas relações entre o Rei e os particulares”, procurando demonstrar a segunda com citação ao Decreto de 21 de maio de 1821, que impôs ao Estado a limitação de que "a ninguem possa tomar-se contra sua vontade cousa alguma de que fôr possuidor, ou proprietario; sejam quaesquer que forem as necessidades do Estado, sem que primeiro de commum acordo se ajuste o preço”, bem como ao anteriormente mencionado art. 22 do Regulamento de 1854 da Lei de Terras (cap. 9 a 12). Defende, citando Teixeira de Freitas, que a legislação imperial não vedou a prescrição aquisitiva sobre terras devolutas, mas impôs aos proprietários o inconveniente de ter que registrar um título de domínio (cap. 13 a 17).

Em seguida, adentra no período republicano e na defesa da sua tese naquele contexto (cap. 18 a 28). O capítulo 29 consubstancia a conclusão, no sentido da prescritibilidade das terras devolutas até 1933 e a artificialidade da tese oposta “tão contrária à realidade brasileira”, pois "o sentido do direito de propriedade no Brasil — di-lo a História - sempre foi o da sua consolidação pela prescrição ou pelo usucapião”, de modo que aceitar a imprescritibilidade retroativa seria “praticamente abolir a propriedade particular em face do Estado [...] [, ] tornar possível a expropriação sem indenização”.

Antes de encerrar, vale destacar que o livro é repleto de afirmações controvertidas, como as de que: o senhor feudal era um “super proprietário” (p. 16); as terras conquistadas pelos portugueses na América eram "propriedade privada” do rei de Portugal, com título de domínio outorgado pelo Papa (p. 26); os proprietários-reis espanhol e português firmaram, em Tordesilhas, mediante procuradores bastantes, uma escritura pública de reconhecimento de limites de suas propriedades, cuja objeção apresentada pelo rei da França seria como a de um "prejudicado" por um "acordo entre grileiros” (p. 31); além da propriedade privada das terras, o rei de Portugal acumulava a soberania sobre todo o Brasil (p. 32); citando Oliveira Viana, “o bugreiro vence o obstáculo material, que é o índio, povoador infecundo da floresta infecunda”, e o grileiro, vencendo o “obstáculo jurídico”, “cria, 
pela chicana e pela falsidade, o indispensável título de propriedade”, enaltecendo “a função social do bugreiro e do grileiro” (p. 59); o “colonizador nacional revela sua superioridade sobre o colonizador estrangeiro” (p. 62); e a prescrição é combatida pelos “'reformadores’ apressados, técnicos de colonisação no asfalto, que jamais sentiram os sacrifícios do sertão” (p. 66). Hoje, a análise dessas assertivas renderia discussões acadêmicas, no mínimo, divertidas.

Concluindo, ainda que se discorde, no todo ou em parte, do conteúdo do livro, ele é leitura obrigatória para quem se dedica ao estudo histórico e jurídico das terras devolutas, da usucapião e da formação da propriedade territorial privada no Brasil.

\section{REFERÊNCIAS}

CABRAL, Carlos Castilho. Terras devolutas e prescrição. Rio de Janeiro: Jornal do Commercio, 1943.

MAXIMILIANO, Carlos. Hermenêutica e aplicação do direito. Porto Alegre: Globo, 1925.

Cláudio Grande Júnior Mestre em Direito Agrário e Especialista em Direito Constitucional pela Universidade Federal de Goiás (UFG). Especialista em Direito Administrativo Contemporâneo pelo Instituto de Direito Administrativo de Goiás (Idag). Membro da União Brasileira dos Agraristas Universitários (Ubau). Ex-Professor Substituto na UFG. Procurador na Procuradoria-Geral do Estado de Goiás (PGE-GO). E-mail: cgrandejr@gmail.com 